\title{
Mapping the Skin and the Guts of Stories: A Dialog Between Conventional and Alternative Cartographies
}

\author{
Sébastien Caquard ${ }^{\mathrm{a}, *}$, Élise Olmedo ${ }^{\mathrm{b}}$ \\ ${ }^{a}$ Concordia University, sebastien.caquard@concordia.ca \\ ${ }^{b}$ Concordia University elise.olmedo@gmail.com \\ * Corresponding author
}

Keywords: Mapping stories; Sensibility mapping; Atlascine; Cartographic dialog; Art maps; Geoweb; Exile; Rwanda

\begin{abstract}
:
Contemporary cartography is increasingly open to the interaction between conventional maps and alternative forms of spatial expressions. A mapping project doesn't have to position itself anymore as either a scientific or an artistic one; it can be both. This rapprochement between what has largely been considered the two ends of the cartographic spectrum, has been encouraged on the one hand by the fascination exercised by maps in the arts and in the humanities as a powerful mean for creative expression and political statements, and on the other by the growing recognition in the social sciences of the potential of art maps to expand our understanding of our relationships to places. This rapprochement has been materialized in a range of geohumanities and deep mapping projects as well as in art map experiments and activist mapping endeavors. In some of these projects, the hierarchy between conventional and alternative forms of mapping has been somehow blurred, opening up new spaces for a real dialog between them.
\end{abstract}

Before engaging in this dialog, let's clarify what we mean by conventional and alternative forms of mapping. Conventional cartography in our books is exemplified by Euclidean or Cartesian maps: maps that are mathematically associated to portions of the earth through geographic coordinates. These maps follow the historical lineage of topographic and thematic maps and include all the maps produced with Geographic Information Systems (GIS) as well as with online mapping services such as Google Maps, Openstreetmap and ArcGIS online. Alternative maps can be broadly considered as "coordinate free mapping". Less common, they encompass maps dissociated from the Euclidean space to focus on non-Euclidean connections to places. To do so, they often revisit the cartographic forms as illustrated in art maps (Harmon 2009; Wood 2010), inductive visualization (Knowles, Westerveld, and Strom 2015) or sensibility maps (Olmedo 2015). Some of these alternative maps have moved outside academia to reach a larger audience (Solnit 2010; DeGraff and Harmon 2015). This growing popularity within and beyond academia opens the possibility for a real dialog with conventional cartography; a dialog based on listening, consideration, exchange and openness to learn from one another.

In this paper we propose to engage a dialog between one particular type of alternative mapping practice (i.e. "Sensibility mapping") and one form of conventional, online cartography (i.e. "Atlascine mapping"). This dialog has been made necessary by the cartographic challenge we have faced: mapping the life stories of Rwandan exiles. The responsibility that comes with mapping such a complex and sensitive type of stories requires careful attention and an openness to diversity of perspectives. It also requires an ongoing dialog between the Western academic mapmakers and the storytellers of Rwandan origin, between those who represent the stories as part of their professional activities and those for whom these stories are central to their life. Beyond this dialog, it is a conversation between two series of maps made by two academic mapmakers who have different but complementary ways of envisioning spatial representations. A conversation that aims to help each of us reflect on our own mapping practices to constantly improve them individually as well as to explore the potential offered by their association.

This dialog and the series of maps produced reveal common ground between these two approaches. Both respect the integrity of the stories, while making the mapping process as transparent as possible. However, they also unveil their differences. Conventional maps designed in this project tend to simplify these stories, they focus on what is explicit in them, on their surface, on their skins to unveil some spatial structures; they perform stories as geographic databases. On the other hand, sensibility maps explore in depth selected fragments of these stories; they look at the inner parts, at their guts. They perform stories as personal and intimate memories. Beyond these differences, it is the complementary of these two approaches that emerge from this dialog: one mapping practice is never enough to reveal both the extent and the depth of complex human experiences of places.

For the full paper, please see: Olmedo E. and Caquard S. (forthcoming 2022), Mapping the Skin and the Guts of Stories - A Dialogue Between Geolocated and Dislocated Cartographies, Cartographica. 


\section{References}

DeGraff, Andrew, and Daniel Harmon. 2015. Plotted: A Literary Atlas. San Francisco, CA: Pulp/Zest Books.

Harmon, Katharine. 2009. The Map as Art: Contemporary Artists Explore Cartography. Princeton Architectural Press.

Knowles, Anne Kelly, Levi Westerveld, and Laura Strom. 2015. "Inductive Visualization: A Humanistic Alternative to GIS." GeoHumanities 1 (2): 233-65.

Olmedo, Élise. 2015. "Cartographie sensible. Tracer une géographie du vécu par la recherche-création." Thèse de doctorat, Université Paris 1 Panthéon Sorbonne.

Solnit, Rebecca. 2010. Infinite City: A San Francisco Atlas. Berkley: University of California Press.

Wood, Denis. 2010. Rethinking the Power of Maps. New York: The Guilford Press. 